\title{
Philippe de Commynes, Mémoires
}

\section{Paola Cifarelli}

\section{Q OpenEdition}

\section{Journals}

\section{Édition électronique}

URL : http://journals.openedition.org/studifrancesi/34438

DOI : 10.4000/studifrancesi.34438

ISSN : 2427-5856

\section{Éditeur}

Rosenberg \& Sellier

\section{Édition imprimée}

Date de publication : 1 novembre 2005

Pagination : 395

ISSN : 0039-2944

\section{Référence électronique}

Paola Cifarelli, « Philippe de Commynes, Mémoires », Studi Francesi [En ligne], 146 (XLIX | II) | 2005, mis en ligne le 30 novembre 2015, consulté le 20 avril 2021. URL : http://journals.openedition.org/ studifrancesi/34438; DOI : https://doi.org/10.4000/studifrancesi.34438

\section{Ce document a été généré automatiquement le 20 avril 2021.}

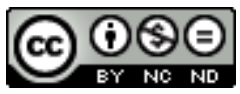

Studi Francesi è distribuita con Licenza Creative Commons Attribuzione - Non commerciale - Non opere derivate 4.0 Internazionale. 


\title{
Philippe de Commynes, Mémoires
}

\author{
Paola Cifarelli
}

\section{RÉFÉRENCE}

PHILIPPE DE COMMYNES, Mémoires. Présentation et traduction par JOËL BLANCHARD, Paris, Pocket, 2004, 794 pp.

1 L'éminent spécialiste de Commynes qu'est Joël Blanchard fournit dans ce riche volume la première traduction en français moderne de l'ensemble des Mémoires de Commynes, qui constituent l'un des documents littéraires les plus importants pour le développement de la prose française. L'auteur, qui motive son travail par la volonté de rendre ce texte complexe plus accessible et contribuer ainsi à une plus vaste connaissance de ce texte lu sans interruptions pendant toutes les époques, fait précéder la traduction par une dense introduction.

2 Dans celle-ci, il met en valeur la signification culturelle de cet ouvrage, en esquissant aussi une biographie de Commynes qui annonce celle, plus vaste, que l'auteur publiera prochainement. Après avoir analysé le sens profond que possède la décision de quitter le camp de Charles le Téméraire et avoir mis en lumière la modernité du mémorialiste, pourtant bien ancré dans son époque, Blanchard prend en compte cinq phases de l'existence commynienne. Tout d'abord, il jette des lumières nouvelles sur la période bourguignonne, la plus obscure et méconnue, en s'appuyant aussi sur des documents inédits et en soulignant la dette culturelle du futur chambellan de Louis XI envers la culture de ce duché. Il se penche ensuite sur le point crucial constitué par l'épisode de la «trahison», justifiée comme un choix précis et cohérent d'un homme (le roi de France) et d'un système de gouvernement (la monarchie légitime et absolue). La troisième étape de ce parcours à travers la biographe de Commynes est représentée par la période passée au service du roi, suivie par le survol de l'intense activité diplomatique auprès de différents gouvernements et tout particulièrement à la cour anglaise et à celle de plusieurs princes et états italiens. Enfin, l'attention se concentre sur son rôle en tant qu'historien et sur sa méthode de travail. 
3 La traduction, enrichie de nombreuses notes explicatives sur les événements évoqués et les personnages cités, est complétée par une bibliograhie sélective et très utile qui signale les différentes éditions des Mémoires, les principaux manuscrits et toutes les études critiques les plus significatives sur l'auteur et son ouvrage. En fin de volume, une série de cartes et de tableaux généalogiques aident le lecteur à s'orienter dans le texte, tandis que l'index des personnes, lieux et matières permet une consultation rapide de l'œuvre.

4 Ce travail, qui s'ajoute donc aux traductions italienne, allemande, hollandaise, suédoise et espagnole exécutées dans le cours des siècles, doit donc être salué comme une entreprise essentielle, car il permet de rendre plus accessible un texte dont la langue, souvent 'rugueuse' (et qu'on s'étonne un peu de voir qualifiée d'ancien français' dans le titre de l'ouvrage) et le style parfois bigarré risquent de faire oublier les qualités littéraires. 